\title{
Effectiveness of Experimental Approaches in Economics: A Case of Ultimatum Games Experiments
}

\author{
Prof. Dr. Yusuf Akan (Atatürk University, Turkey) \\ Ph.D. Candidate Aslı Cansın Doker (Erzincan University, Turkey)
}

\begin{abstract}
In economics theory literature, it has been a crucial question whether experiments can be helpful to test theory in laboratory. Since late 1940s experimental methods has been found useful in economics however there is still some doubts about unbiasedness, ability to test. The essential of economics theory is related to mathematics resulted of this deductive reasoning to inductive one with using time series data and statistical analysis. Additionally, generally in experiments and its sessions, undergraduate or graduate students are generally chosen as participants by researchers, this brings several doubts and questions together such as reliability on their choices, power of explanation and also restrictions about rationality of players which are decision makers as individual. After the 1950s with the introduction of game theory, experimental methods have been strong placed in the research. Especially market designs, rationality and behavioral design have been subjected to experiments. However, it is still crucial question whether those experimental methods could be effective or not. This study will be discussed experimental methodology with game theoretical approach using trust and ultimatum games perspective. In addition, giving the structure of the sessions and experiments, the regulations and steps will be figure systematically. This study will be discussed rational individual decision making process and try to explain how chosen games can be lasted more effective.
\end{abstract}

\section{Introduction}

Economics and many social sciences have used game theory applications; the bargaining game is the most common game in politics and economics situations and it is still unclear in the literature of the role of mediators in the bargaining process. With either complete or incomplete information bargaining processes, bargaining has some threats which can be fixed or variable, and the expectations of players has important effects on the bargaining. In this paper, mediated bargaining will be discussed, firstly the game theoretical aspect with some empirical evidence to support the theory. Often, international negotiations may well be explained with a bargaining game with mediator, for instance, the United Nations (UN) sends a couple of diplomats as mediators to help to reach an agreement in the bargaining process between two parties representing two different countries. The common example of an international bargaining game is between Russia, formerly the United Soviet Socialist Russia (USSR), and the United States of America (USA). Another common use of bargaining game applications is in economics, such as within monopolistic and duopolistic market solutions. In the literature about bargaining games, there are two approaches discussed, which are the strategic approach and the axiomatic approach. Under the Strategic approach, the players' movements are under the assumption of rationality, as expressed by the Nash equilibria. On the other hand, the strategic method has some inherent difficulties and with the axiomatic approach these difficulties adjust the specified assumptions (Rubenstein, 1982).

The main questions about the bargaining situations are generally "what will be the agreed contract under rationality assumption for players?", and also what is the effect of the strategic mediator type? What is the effect of players' type in the bargaining game? After those questions one more critical statement appears, which is if there is mediator and also as a factor a which is symbolized as biased for mediator "is trust important for a bargaining game" and "does it affect the welfare function?". The researcher has followed Friedman's (1953) positivist perspective. According to Friedman (1953), economics and all social sciences can have the same aspect to their data and analysis as natural science does. On the other hand, Hausmann (1989) states that normative and positive philosophies of methodology can work together in economics. In addition, the researcher should be objective during the analysis part of the study because as a definition of normative perspective in social sciences this avoids bias (Hausmann,1989). Experimental designing of bargaining games can be placed in the literature as public good games or ultimatum games.

Under Harsayni and Selten's (1972) bargaining game model, the utilities, or game outcomes, for each player will depend on both players' types, which are $\mathrm{k}$ and $\mathrm{m}$. This can be shown with a bimatrix form such that;

(1.1) $\mathrm{K} \times \mathrm{M}$ is the bimatrix form of the utilities for all agreement points

$$
\mathrm{u}=\text { uikm } \quad \mathrm{i}=1,2 . \quad \mathrm{k}=(1,2, \ldots . \mathrm{K}) \quad \mathrm{m}=(1,2, \ldots . \mathrm{M})
$$

The explanation of the 1.1 equation is that player $\mathrm{i}$ and uikm shows the $\mathrm{k}$ or $\mathrm{m}$ type player i's payoff which he will get from the agreement point.

$$
\text { (1.2) } \mathrm{c}=\mathrm{cikm} \quad \mathrm{i}=1,2 . \quad \mathrm{k}=(1,2, \ldots . \mathrm{K}) ; \quad \mathrm{m}=(1,2, \ldots . \mathrm{M}) \text {; }
$$


With actual types $\mathrm{k}$ and $\mathrm{m}$ of player 1 and player 2 respectively, $\mathrm{c}$ is the conflict points set of the game. In other words, $\mathrm{c}$ is the set including payoffs of player 1 and 2 from the conflict situation of the bargaining process. Another assumption of the game is following such that players are free to bring their action to the conflict point if they desire this. After definition of those assumptions the bargaining process with incomplete information can be examined with notation $\mathrm{S}$ below;

$$
\mathrm{S}=(\mathrm{U}, \mathrm{c}, \mathrm{r}) \text {, where }
$$

$\mathrm{U}$ : all feasible agreements

c: conflict points which is also sub set of the $U$

r: probability bimatrix

Harsayni and Selten, Nash and Rubenstein bargaining games have some differences which will be discussed step by step in the next part.

In the late 1950's, Nash examined the reduced form approach in cooperative games which is now the most common and known application for game theorists. Nash's aim is to pick axioms which can characterize the agreement point for players so that they can negotiate with each other.(Nash,1950) Basically he examined a game similar to the splitting of pie game, only more complicated. In Nash modelling, there are two players and they may have different utilities; if they don't reach agreement, the utility functions can be nonlinear, regardless of sharing of the pie (Ausubel, M., et al.,1993; Nash,J.,1950). The differences between these two games will be shown in Figure 2. It is generally considered that cooperative bargaining games are fairer, more moral and more efficient than a non-cooperative bargaining process. (Donni, O. and Chiappori, P.,2006.;Nash,1950)

In Nash bargaining analysis, all bargaining situations which are show by $\mathrm{S}$ are defined by the payoffs set which is called U. Similarly in NS, players can meet at a point in a feasible agreement set or can meet at a point in a conflict set. As a result the bargaining situation in NS can be written formally as;

$$
S=(U, c)
$$

As can be seen, the difference between equation (2.3) and (3.1) in NS the bargaining situation does not have a probability set as a subset of S. The explanation is that in the NS bargaining game there is complete information related to this and there is only one possible type of player, as shown in (2.2);

(2.2) If there is complete information $K=M=1$.

Another assumption in NS is the independency of players' actions. Nash(1950) has proposed that the equilibrium points in the bargaining process are given by payoff points which are in the feasible set $U$, and he has shown the reservation values with inequalities such that;

(2.3) $u_{i} \geq c_{i}$

$$
i=1,2 \text {. }
$$

$\operatorname{Nash}(1950)$ argues that there is always a unique solution if the bargaining process can prove that these axioms exists. If we take one point which is $u=\left(u_{1}, u_{2}\right)$, then using this point the Nash product will be;

$$
\pi=\left(u_{1}-c_{1}\right) \cdot\left(u_{2}-c_{2}\right)
$$

Above, the Nash solution's first step in a bargaining game with complete information has been discussed. The next step will be analysing bargaining situations with incomplete information in NS. Harsayni and Selten (1972) discussed the bargaining game with incomplete information with using and examining the Nash Solution's axioms, but they needed a more complicated model than Nash's complete information bargaining model. This model will be discussed and a mediator position or role will be added to the equation, however before that there are some important axioms in NS which compose the NS characteristic features.

\section{Public Good Games and Experimental Applications}

Public Good Games has been evaluated for testing assumptions of homoeconomicus in economics theory which is strongly important for all applications. This can be explained how to behave consumer or firm in business cycle and also how to make economic decision in which period of time. There are some types of game applications under the public good games; dictator game, ultimatum games and gift games respectively. Before explanations in detail of those, the process of an experimental design is discussed. Previously it has been discussed above the main assumptions, additionally testing this theory will be in experimental laboratory which can be real life examples ebay costumers' consumption decision process, public share in society with extarnatlies or in game design special laboratory. For the game design analyst is the controller of the experiment and he is responsible of the clients' behaviors and unexpected situation out of the game. His first role in the experiment will be decided to inform the clients about the chosen game rules and reward or punishment of the pay offs. After these information, the game sessions will be started however the game can be full informative or incompletely informative, this is about the analyst' study question. Moreover, the experiment results will be collected and interpreted by the economist to check rationality and other strict assumptions whether those behavioral movement supported the theory with delays or not and also those experiments may well end with the conflict. Conflicts is also an explaition for the unbalancity in the economy. Figure 1 is one of the example of the process on bargaining situation. 


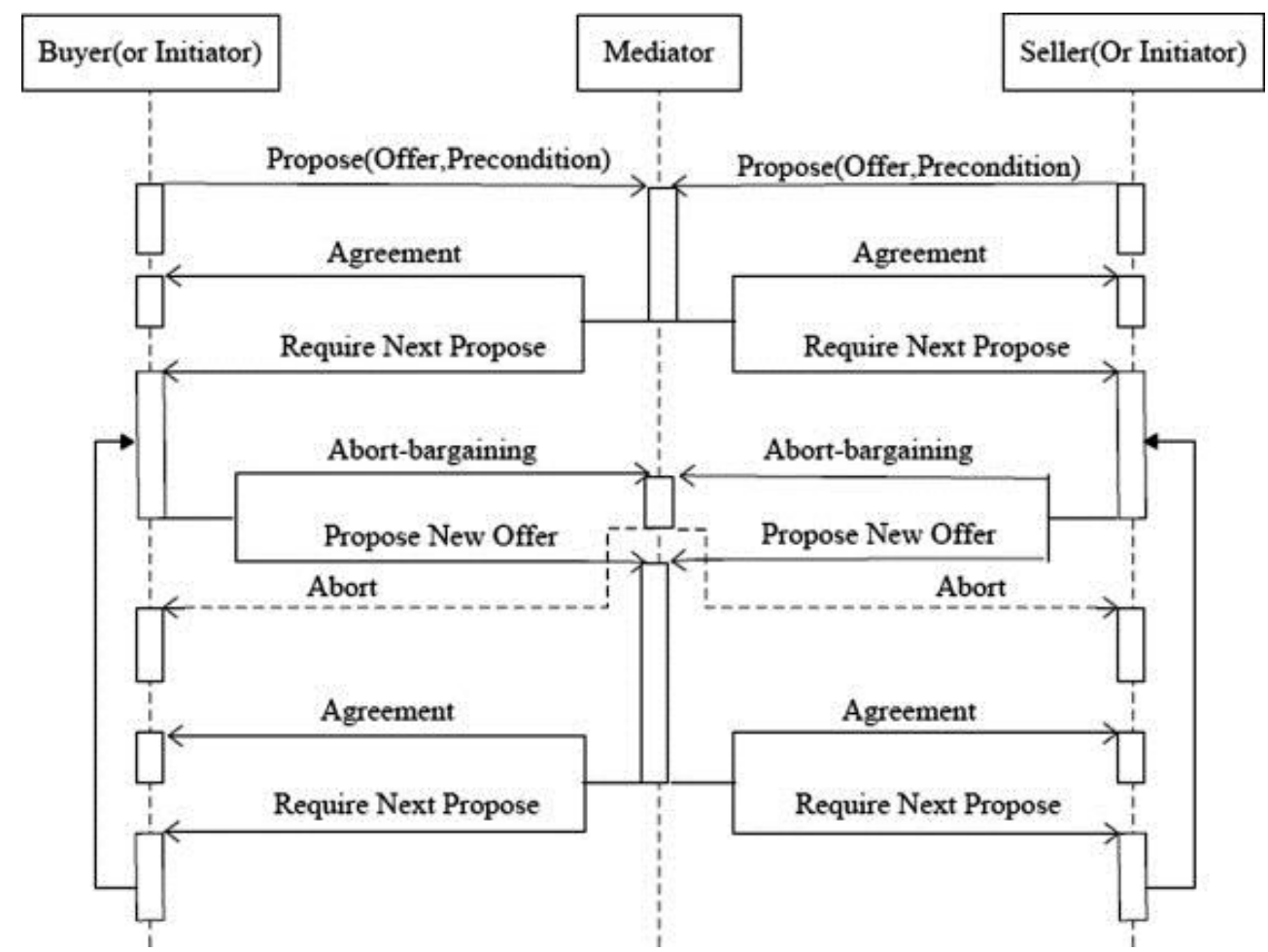

Figure 1: The Schematic of the Mediation Process: Bargaining Game with Incomplete and Complete Information

Public Good Games was improved for group behaviors on the other hand dictator games and ultimatum games is discussed individual behavior under the economic activities. For designing experiments, generally undergraduate students are chosen as players or party of the situation. The controller of the game is the researcher who is the responsive of the crying rules and information under the sessions. Bargaining game with mediation can be placed in the ultimaotom experiments with its lemma and assumption. In this paper, it was discussed under incomplete bargaining process whether end with conflict or not.

\section{Conclusion}

This paper has proposed to show how the mediation process can be helpful for an efficient bargaining game. There are several previous findings to support this paper's aims; on the other hand, in this paper the researcher designed a mediated bargaining game with incomplete information and used some assumptions from main game theoretical papers. Before having designed the game, perfect equilibrium, Nash solution, Harsayni and Selten (1972) bargaining and Rubeinstein (1982) bargaining game have been discussed. After those discussions, the researcher used the two person bargaining game and the game has been started with the splitting pie game with normalized pay size. In addition, the chosen distribution for utility function is uniform and the rules of the game were discussed and put forward. Moreover, the preliminaries, which consist of axioms and lemmas which show whether or not the solution of the game is useful and efficient. This game has the same axioms as the Rubenstein bargaining (1982) game with incomplete information, however the main difference between this game and Rubenstein game is using a third party, which is having a mediator. Furthermore, timing in the game has been chosen to be continuous, the pie is desirable, and another significant point is that there are no monetary stakes in this bargaining process. In this study, it is shown that a fixed cost of bargaining and a fixed surplus discount rate in the bargaining process helps to reach an agreement point fast and also reduces conflicts. This paper examined and showed mediation in bargaining situations using monotonicity lemma and opponent's strategic best response, which are necessary to get a general solution and interpretation of the game. Depending on this statement, the mediator still has a critical role in this game. It is still recommended using mediated bargaining game in politics and also economics to reach an agreement easily and create more efficient bargaining situations. In addition, timing preferences, as discussed briefly, can cause a delay of agreement and reduce the efficiency of bargaining (Rubenstein, 1985). In this paper, the researcher did not choose a general solution for the N-person game; the reason for that is the research time was not sufficient to reach a general solution. However, it is necessary to put a few recommendations for future studies. First, there is still one important discussion which this paper cannot address, namely the effects of the bias of a mediator who is active in the mediation process; this discussion can be linked with cheap talk, which is another important game with different credibility and reputation assumptions. In conclusion experiments which is still crucial discussion in the literature, can be helpful a for explaining person's 
role in the economics theory. Moreover, Game experiments are more acceptable with mathematical assumptions and lemma because, those can be controlled the rationality.

\section{References}

- Abreu, D. and Gul F., 2000. "Bargaining and reputation”, Econometrica, Vol.68, pp85-117.

- Ausubel, M., et al.,1993. "Efficient Sequental Bargaining”. Review of Economic Studies, Vol.60, pp.435461.

- Chatagnier, Tyson J., 2012. "Mediation and the Effects of Third Party Observation"

- Chatterjee, K. and Samuelson, W.F.,1987. "Bargaining with two-sided incomplete information," Revision Economics Studies, Vol.54, pp.175-192.

- Cross, John G.,1965. “A Theory of the Bargaining Process”, The American Economic Review, Vol. 55, pp. 67-94.

- Donni, O. and Chiappori, P.,2006. Learning from a piece of pie: The Empirical Content of Nash Bargaining. Iza Discussion Paper, No.2128,04/2006. Available at:

- Dunlop, J.T. (1984): Dispute Resolution, Auburn House, Dover MA.

- Fey, M. and Ramsay, K., 2010. "When Is Shuttle Diplomacy Worth the Commute?: Information Sharing through Mediation". World Politics, Vol.62, pp.529-560. Available at : http://muse.jhu.edu/journals/wp/summary/v062/62.4.fey.html

- Friedman, M., 1984. Essays in Positive Economics. 4th Edition. Chicago: University of Chicago Press.

- Fudenberg, D. and Tirole, J.,1986. “A theory of exit in Duopoly”, Econometrica, Vol. 54, pp.943-960.

- Goltsman, M., et al., 2009. "Mediation, arbitration and negotiation", Journal of Economic Theory, Vol.144, pp. $1397-1420$

- Harsayni, John C.,1956. "Approaches to the Bargaining Problem Before and After the Theory of Games". Econometrica, Vol.24, pp.144-157.

- Harsanyi, John C. and Selten R.,1972. "A Generalized Nash Solution for Two-Person Bargaining Games with Incomplete Information", Management Science, Vol. 18, No. 5, pp.80-106.

- Hausmann, D.,1989. "Economic Methodology in a Nutshell”, Journal of Economic Perspectives, Vol.3, No.2,pp.115-127.

- Ivanov, M.,2010. "Communication via a strategic mediator". Journal Economic Theory, Vol.145, pp.869884Avalibleat: http://www.sciencedirect.com/science/article/pii/S0022053109001100

- Jarque, X. et al.,2003. "Mediation: Incomplete information bargaining with filtered communication”, Journal of Mathematical Economics, Vol.39, pp.803-830.

- Kydd, A. 2003. "Which side are you on? Bias, credibility, and mediation”, American Journal of Political Science, pp. 597-611.

- Kydd, A. 2006. “When Can Mediators Build Trust?”, American Political Science Review, Vol.100, pp.449462.

- Lehrer, E., 1996. “Mediated Talk”, International Journal of Game Theory, Vol.25, pp.177-188.

- Myerson, R. and Satterhwaite, M.,1983. "Efficient Mechanisms for Bilateral Trading”, Journal of Economic Theory, Vol.29, pp.265-228. war of

- Nash, John F.,1950. "The Bargaining Problem”. Econometrica, Vol.18,pp.155-162.

- Ponsati, C. and Sfikovics, J.,1995. "The war of attrition with incomplete information”. Mathematica Social Sciences, Vol.29,pp.239-254.

- Ponsatí, C.,1995. "Compromise vs. Capitulation in Bargaining with Incomplete Information”, Annals of Economics and Statistics, Vol.48,pp.191-210.

- Peng, Z., "An novel ADM for finding Cournot equilibria of bargaining problem with alternating offers" Unpublished thesis, (PhD), NanJing University.

- $\quad$ Rice, A.,1979. “Turkey and Cyprus”. Foreign Affairs Vol. 58, No. 2, pp. 408-411.

- Rubenstein, A., 1982. "Perfect Equilibrium in Bargaining Model”, Econometrica, Vol. 50, No.1.

- Rubinstein, A.,1985. "A Bargaining Model with Incomplete Information About Time Preferences", Econometrica, Vol. 53, No. 5, pp. 1151-117.

- Rubenstein, A., 1983 The choice of conjectures in a bargaining game with incomplete information. In: C.V. Starr Center for Applied Economics, New York, September,1983. New York, New York University, pp.2-27. 
- Sákovics, J.,2004. “A Meaningful Two-Person Bargaining Solution Based on Ordinal Preferences”,

- Savun, B., (2006) Information, Bias, and Mediation Success: Evaluating the effectiveness of Mediation of International Conflicts. Unpublished Thesis (PhD), Rice University.

- Ståhl, I.,1973. "Bargaining Theory”. The Swedish Journal of Economics, Vol. 75, No. 4, pp. 410-413.

- Terris, Lesley G. and Maoz Z.,2005. "Rational Mediation: A Theory and a Test”, Journal of Peace Research, Vol.42, pp.563-583.

- Ugur, M.,2010. “Open-Ended Membership Prospect and Commitment Credibility: Explaining the Deadlock in EU-Turkey Accession Negotiations” JCMS: Journal of Common Market Studies. Vol.48, pp.967-991.

- Wilson, Charles A., 2001. "Mediation and the Nash bargaining solution". Review of Economic Design, Vol.6,pp.353-371.

- Wilson, C.,2001. "Mediation and the Nash bargaining solution", Revision of Economic Design, Vol.6, pp.353-370. 